\title{
VENTAJAS E INCONVENIENTES DEL COOPERATIVISMO AGRARIO PARA EL DESARROLLO REGIONAL ARAGONES.
}

\author{
José Luis RUBIO GRACIA \\ Universidad de Zaragoza
}

\begin{abstract}
RESUMEN: El cooperativismo agrario aragonés es una forma de organización que, como en muchas otras regiones, nació con una carga ideológica todavla lalente: esa carga ideologica lleva a concebirlo como la solución a los problemas del campo y propicia planteamientos a veces incorrectos. El estudio pretende analizar las ventajar y, sobre todo, por menos estudiados, las limitaciones e inconvenientes del cooperativismo en el momento actual. El objetivo es valorar con criterios racionales su previsible eficacia ante las exigencias actuales de productividad y viabilidad de las explotaciones y antes los requerimientos del desarrollo rural aragonés.
\end{abstract}

\begin{abstract}
The agricultural co-operative system was born in Aragon, as in many other regions, with an ideological load that still is latent. This load brought it to be considered as a solution to rural problems, raising some incorrect oullines. The aim of this study is to analyse the advantages and, above all, the limitations and disadvantages of the co-operative system at the present time. Its efficacy before the current productivity requirements and the viability of these exploitations are valued with rational criteria.
\end{abstract}

Sumario: 1. Introducción.- 2. Situación actual del cooperativismo agrario aragonés.- 3. Las cooperativas y el desarrollo rural.- 4 . Conclusiones.

\section{INTRODUCCION}

El cooperativismo es un fenómeno social a la vez que económico cuya historia está repleta de acontecimientos decisivos para la vida de muchos municipios. Nació como una manera de redimir el campo mediante la unión de esfuerzos productivos, lo que le imprimió una carga ideológica que lo convirtió en un movimiento social de envergadura. Así, surgieron sindicatos agrarios que se aglutinaron en formaciones políticas reivindicativas y en asociaciones de inspiración religiosa como la Confederación Nacional Católica Agraria. A medida que se ha modernizado el campo, el cooperativismo ha perdido ideología en beneficio de enfoques más economicistas, encaminados a mejorar las estructuras productivas y comerciales.

En Aragón el cooperativismo agrario ha contribuido de una manera decisiva a la transformación del campo. Y todavía hoy la cooperativa es la única organización suprafamiliar de muchos municipios. Aunque no es el momento de explicar este hecho, podrá comprenderse su transcendencia en las líneas que siguen cuando se vea cl volumen comercializado por las cooperativas aragonesas puesto en relación con la producción agraria de las provincias.

Sin embargo, el sector agrario regional se halla en la tesitura de encarar el reto de la integración en la Comunidad Económica Europea. que va a exigir transformaciones profundas del sector. El objetivo del análisis consiste precisamente en examinar el papel del 
cooperativismo agrario en el nuevo entorno comunitario, y su contribución al desarrollo regional en el futuro inmediato.

\section{SITUACION ACTUAL DEL COOPERATIVISMO AGRARIO ARAGONES}

Ya se ha esbozado que en muchos pueblos la cooperativa es el exponente de la vida económica; a su través se obtiene y vende el vino, se moltura la oliva, se comercializan cereales o alfalfa, o se hace la provisión de plaguicidas, abonos minerales y utillaje. Con el paso de los años, la cooperativa se ha convertido en algo consustancial al municipio y se ha erigido en la entidad sobre la que gravita la economía municipal. Por otra parte las cooperativas han desempeñado una función nada desdeñable en la organización del espacio agrario y muchas veces la eficacia del sistema comarcal de cultivos está intimamente relacionada con la eficacia de la gestión de sus cooperativas. Asi, se ha comprobado en muchas comarcas que, independientemente de los vaivenes económicos, alli donde existe cooperativa vinícola se ha mantenido el cultivo de la vid, mientras en otras, sin que diferencias litológicas o climáticas lo justifiquen, ha desaparecido el viñedo o tiende a desaparecer por la ausencia de un sistema organizativo capaz de integrar producción y comercialización.

En Aragón se ha constatado lo que ocurre en otras regiones: cuanto más dificil es para el agricultor vender un producto tanto menor es su interés por producirlo. Esto es transcendental para comprender las transformaciones del espacio agrario y el interés de los agricultores por lograr fórmulas cooperativistas de comercialización: la supervivencia de su sistema productivo está en juego.

No se entrará en la historia del cooperativismo aragonés lo cual alejaría el objetivo, pero si conviene llamar la atención en lo que concierne a la evolución reciente del cooperativismo y a su dispersión por el territorio regional. De esa manera se comprenderá cómo las cooperativas han venido a socorrer situaciones críticas de los agricultores y han actuado como mecanismos de defensa para proteger "status quo" en lo relativo a cultivos y estructuras productivas.

Como se ha dicho, el cooperativismo moderno aragonés tuvo una carga ideológica importante en sus comienzos y, a partir de la entrada en vigor de la ley de cooperativas de 1942 , se impulsó a través del vino, el aceite y los servicios que parećán los productos más adecuados para iniciar la andadura cooperativa. Ante los problemas de la fruta -poca producción en aquellos momentos, naturaleza perecedera de los productos, riesgos de comercialización, complejidad de manipulación- y el control de los cereales a través del Servicio Nacional del Trigo, el vino y el aceite eran idóneos para el sistema cooperativo; no sólo podían soportar la elasticidad de la demanda, sino que además no ofrecían problemas de manipulación, requerían poca mano de obra y su comercialización no planteaba dificultades serias. Además tampoco se necesitaba un nivel de especialización alto para regir una cooperativa de esas características.

Hasta los años setenta el cooperativismo se circunscribió a las comarcas vinícolas y aceiteras: el Jalón, el Jiloca, la tierra de Belchite, el Bajo Aragón y el somontano oscense.

En todas ellas, el cooperativismo ha fijado los cultivos de la vid y el olivo y las transformaciones productivas han sido mínimas. Las variedades de la vid que se cultiva son prácticamente las mismas que hace veinte años; la dimensión de las explotaciones apenas se ha modificado; las parcelas siguen teniendo el mismo tamaño; sólo ha cambiado el proceso de 
transformación de la uva que de hacerse en trujales familiares se hace en la cooperativa. La misma explicación vale para la oliva: las almazaras sustituyeron los molinos de aceite y los olivares han languidecido por la pérdida de competitividad con las producciones de otras regiones, pero apenas se ha hecho esfuerzo alguno de reconversión o transformación de variedades. Las cooperativas cumplieron un papel primordial en la mecanización de una parte del proceso productivo pero anularon las iniciativas de futuro que pudiera haber en los municipios. Aquí radica precisamente una de las deficiencias más importantes del movimiento cooperativo, en cuyo detalle se entrará más tarde.

A medida que la producción de cercales se diversifico; y una vez desaparecido el Servicio Nacional del Trigo, muchas comarcas cerealistas vieron en el cooperativismo una fórmula de comercialización en común. El Servicio Nacional de Productos Agrarios -SENPA- contribuyó a ello mediante la concesión de primas de almacenaje, que resultaban suficientes para cubrir los gastos fijos de la cooperativa. Durante los años setenta floreció el cooperativismo en Cinco Villas y en general en los secanos oscenses y zaragozanos sin tradición vitícola. Por supuesto también se crearon secciones cerealistas en muchas cooperativas tradicionales.

Mención aparte merecen las cooperativas de los nuevos regadíos, frecuentemente asociadas a las cerealistas. Se trata de cooperativas para la comercialización comunitaria de maiz y alfalfa; cuyo exito ha sido tal que el cooperativismo se ha extendido a los regadíos viejos del Ebro, en fechas recientes.

El panorama del cooperativismo se completa con las cooperativas frutícolas y ganaderas. Su número es relativamente pequeño pero tiene su explicación. Su difusión es reciente y el funcionamiento mucho más complejo que en cualquiera de las modalidades anteriores. Se trata de auténticas empresas bajo un régimen jurídico diferente al de las sociedades anónimas y por lo tanto su gestión tiene las exigencias propias de éstas.

Una vez hecho este repaso histórico, parece pertinente examinar la importancia del cooperativismo agrario en Aragón. Por lo cual, nos apoyaremos en dos indicadores: el número de cooperativas y de socios y el volumen de negocio que generan.

En Aragón hay 184 cooperativas en funcionamiento real, según encuesta propia realizada al efecto. Ya se ha visto que el cooperativismo nacio en los somontanos pero progresivamente ha invadido casi todo el espacio regional y destaca por su número la provincia más agrícola que es Zaragoza.

En Zaragoza se suman las cooperativas vitivinícolas y almazaras, de larga tradición, y las más modernas de cereales, ganaderas y frutícolas. Le sigue en número la provincia de Teruel que concentra las cooperativas en el Jiloca y el Bajo Aragón; también en este caso se reproduce lo dicho acerca de Zaragoza, con la particularidad de que aquí las cooperativas tradicionales han creado secciones frutícolas para comercializar en común el melocotón y han ampliado su función con secciones cerealistas, de comercialización de almendras, etc. Huesca, por su parte, tiene pocas cooperativas, porque el fenómeno afecta sobre todo a los nuevos regadíos, con cooperativas cerealistas y frutícolas.

El número de socios es anormalmente alto. Scgún datos de la Renta Municipal de Aragón para 1981, la población ocupada en el sector agrario en la provincia de Zaragoza ascendía a 31.167 personas y el número de socios en cooperativas es de 34.986. Obviamente no hay relación entre ambas cifras y las conclusiones que de ello se derivan pueden hacerse extensivas a Huesca y Teruel. 
Las explicaciones pueden ser muchas, pero hay dos que parecen más destacables. Por un lado, el que hay socios que lo son de varias cooperativas, aunque su número no parece que sea suficiente para justificar la desproporción, habida cuenta de que muchos municipios no tienen cooperativas. Por otro, y esta razón se nos antoja de más peso, hay muchísimos socios que lo son de derecho pero no de hecho. Se trata de emigrantes que conservan la condición de socios porque son titulares de viñedos, olivares, frutales o tierras cercalistas que cultivan bajo cualquier forma de arrendamiento o aparcería. A ellos se añaden los agricultores jubilados residentes en el municipio que tampoco cultivan directamente las tierras, y los absentistas, en general.

\section{COOPERATIVAS Y SOCIOS EN ARAGON}

\begin{tabular}{|c|c|c|c|}
\hline Provincia & N. Cooperativas & N. Socios & Socios/Cooperativa \\
\hline Huesca & 29 & 7.340 & 253 \\
\hline Teruel & 41 & 8.681 & 212 \\
\hline Zaragoza & 114 & 34.986 & 307 \\
\hline ARAGON & 184 & 51.007 & 277 \\
\hline
\end{tabular}

* Sin los socios de C.A.O.

\section{Fuente: Encuesta propia.}

Ambos hechos son trascendentales de cara al desarrollo agrario porque la cooperativa contabiliza un activo humano absentista o poco predispuesto a las innovaciones. Además el propio sistema cooperativista hace posible que perduran estas situaciones de evidente despilfarro de recursos, desde el momento en que la cooperativa, forzada por la presión social, tiene que asumir funciones productivas que corresponderían al agricultor individual. Veamos algunos ejemplos: la cooperativa de Alagón está dotada de un parque de maquinaria que limita la función del agricultor a los riegos; tanto las labores como la recolección de maiz o alfalfa corren a cargo de la cooperativa. La cooperativa de la Almunia también efectúa todos los tratamientos fitosanitarios para homogeneizar calidades y el agricultor poda, riega y recolecta. En Báguena (Teruel) la cooperativa tiene tractores de rueda de goma y oruga, de manera que efectúa las labores por cuenta de los socios favoreciendo sobre todo a los absentistas.

Es evidente que en estas circunstancias se restringe la venta de tierras y el acceso a la propiedad de nuevos agricultores y en suma se ralentiza la necesaria transformación de las estructuras productivas. Por eso no debe sorprender que el fenómeno cooperativo afecte sobre todo a los cultivos de mecanización más fácil.

En Aragón hay 100 secciones cooperativas de cereales, 58 vitivinícolas, 43 almazaras y 60 de maiz y alfalfa. Por el contrario hortofrutícolas sólo hay 46 , a las que habría que deducir muchas cuya única función es venta en común, sin selección, conservación ni transformación alguna en régimen cooperativo. 
SECCIONES DE COOPERATIVAS AGRARIAS EN ARAGON (1987)

\begin{tabular}{|c|c|c|c|c|}
\hline Seccioncs & Hucsca & Teruel & Zaragoza & Aragón \\
\hline Cercal & 23 & 14 & 63 & 100 \\
\hline Uva/vino & 1 & 11 & 46 & 58 \\
\hline Aceite & 1 & 23 & 19 & 43 \\
\hline Fruta & 6 & 24 & 16 & 46 \\
\hline Maiz & 7 & -- & 40 & 47 \\
\hline Alfalfa & 2 & -- & 11 & 13 \\
\hline Almendra & 2 & 12 & 9 & 23 \\
\hline Ganadería & 1 & 5 & 4 & 10 \\
\hline TOTAL & 43 & 89 & 208 & 340 \\
\hline
\end{tabular}

Fuente: Encuesta propia

\section{ESTIMACION DEL VALOR DE LA PRODUCCION COMERCIALIZADA POR LAS COOPERATIVAS ARAGONESAS EN 1987 (Millones de ptas.)}

\begin{tabular}{lr} 
Producto & Millones \\
\hline Cereales & 14.550 \\
Vino/uva & 3.824 \\
Aceite & 1.347 \\
Fruta & 3.798 \\
Maiz & 8.878 \\
Alfalfa & 869 \\
Almendras & 808 \\
Ganadería & 2.957 \\
& -1.94 .041
\end{tabular}

Fuente: Encuesta propia.

Al cooperativismo se han atribuido excelencias que no son tales. Es habitual considerar que comercializando en común se obtienen precios mejores y esto no es totalmente exacto, porque la cooperativa no fija precios, ya que estos responden a decisiones macroeconómicas de ámbito nacional o supranacional. Con la cooperativa se concentra la oferta pero no se solucionan las deficiencias productivas estructurales. Hay que valorar que el minifundismo productivo que impera en Aragón por el que se hinchan los costes de producción no se resuelve con la concentración de la oferta; cn cambio la cooperativa concentra riesgos al asumir la responsabilidad de vender el producto de muchos agricultores y su oferta se torna muy inelástica. Por eso es frecuente la desconfianza de los agricultores, cuando sucesivamente ven que los precios obtenidos por su cosecha vendida libremente son superiores a las que reporta la cooperativa. El número de cooperativas que se constituye con ilusión enorme y que languidecen en pocos años es revelador de todo este. 
Y eso ocurre porque cl cooperativismo no nace como solución para evolucionar en una economía de libre mercado, sino para defender estructuras productivas heredadas y sistemas de cultivo tradicionales, como se ha indicado ya.

ESTIMACION DEL VALOR DE LA PRODUCCION COMERCIALIZADA POR LAS COOPERATIVAS EN \% SOBRE EL VALOR DE LA PRODUCCION PROVINCIAL (1987).

$\begin{array}{lccc}\text { Producto } & \text { Huesca \% } & \text { Teruel \% } & \text { Zaragoza \% } \\ \text { Cereales } & 54 & 33 & 56 \\ \text { Vino/uva } & 50 & 83 & 91 \\ \text { Aceite } & 12 & 82 & 92 \\ \text { Fruta } & 17 & 75 & 19 \\ \text { Maiz } & 57 & -- & 64 \\ \text { Alfalfa } & 2 & -- & 36 \\ \text { Almendras } & 7 & 34 & 59 \\ \text { Ganadería } & 1 & 13 & 22\end{array}$

Fuente: Encuesta propia

Sin embargo, hay que conceder al cooperativismo el valor social y económico que ha alcanzado. El valor social está fuera de duda, desde el momento en que la cooperativa es una manera de sostener las rentas de agricultores que en nuestra sociedad de libre mercado hubieran peligrado; pero a medida que se afianzan las orientaciones economicistas, queda en entredicho. Aún así, el cooperativismo aragonés tiene un peso económico indudable.

Según nuestras estimaciones el volumen de facturación de las cooperativas aragonesas ascendió en 1987 a 37.041 millones de pesetas. Las cooperativas son el sostén de cultivos como la vid y el olivo en Teruel y Zaragoza. También es fundamental su intervención en la producción de cereales en Huesca y Zaragoza, de mclocotón en Teruel, de maiz y alfalfa en Zaragoza. Por otra parte, aunque no se recoge en los cuadros adjuntos, las cooperativas desempeñan un papel capital en el suministro de fertilizantes, plaguicidas y otros "inputs" necesarios en el medio rural. Evidentemente esta función está ligada al minifundismo del sector, tanto en lo parcelario y explotaciones, como de producción que las cooperativas contribuyen a sostener.

\section{LAS COOPERATIVAS Y EL DESARROLLO RURAL}

El sector agrario europeo y por tanto el aragonćs camina hacia fórmulas cada vez más liberales. La Política Agraria Común (PAC) actual de la CEE supone una carga financicra muy pesada que los gobiernos comunitarios descan aligerar. Ello implica que las medidas proteccionistas están en regresión y que la agricultura debe buscar su supervivencia en el contex to de una sociedad de mercado cada vez más competitiva c internacionalizada.

En este contexto el desarrollo rural como generalización del agrario, ha de conseguir estructuras productivas acordes con la sociedad de mercado y con las perspectivas liberalizadores que permite vislumbrar el Acta Unica Europea. Dada la importancia social y 
económica de las cooperativas en el campo aragonés parece imprescindible valorar su aportación respecto de esos objetivos.

El balance del cooperativismo que nace con la ley de cooperativas de 1942 arroja un saldo final impreciso, como se deduce del apartado anterior. Parece favorable en lo social, pero en lo económico no está tan claro; y profundizando un poco más, puede decirse que su intervención en la ordenación rural también ha sido decisiva pero de resultado discutible.

En su haber hay que contabilizar por ejemplo:

* El desarrollo del principio de solidaridad.

* La mecanización de procesos productivos.

* La continuidad de las producciones agrícolas en espacios marginales.

* La contribución en orden a integrar agricultura e industria.

* La prestación de servicios en comunidades rurales poco dotadas.

* Concentración de la oferta productiva de los municipios para su comercialización. mercado.

* El mantenimiento de rentas agrarias de difícil pervivencia en una sociedad de

Las partidas de "debe" también son importantes y en ellas habría que incidir para mejorar el papel futuro de las cooperativas. Cabe destacar las siguientes:

* Carga ideológico-política del cooperativismo a lo largo de su historia.

* Desarrollo del cooperativismo en actividades -cultivos- en declive, necesitadas de reconversión.

* Ralentización del cambio de estructuras productivas.

* Impedimentos a las iniciativas particulares ante la presión de la imagen de insolidaridad cooperativa.

* Fomento de la agricultura a tiempo parcial.

* Restricciones al acceso a la propiedad de agricultores jóvenes, con el impedimento de la racionalización del tamaño de las explotaciones al fomentarse el absentismo.

* Contribución a la explotación agraria bajo regímenes de arrendamiento o aparcería.

La lista de aspectos negativos podría ampliarse, si se entrara en más detalles, pero parece suficiente para los objetivos de este trabajo. Casi todos los inconvenientes enumerados tienen algo que ver con el desarrollo rural, y merece mención especial lo relativo a las restricciones a la modernización del campo aragonés.

Se ha dicho antes que las cooperativas tuvicron un papel primordial en la mecanización de procesos en determinado momento -vitivinícolas y almazaras- pero apenas llegaron más lejos. En su afán igualitarista, la equidad ha sido un objetivo a conseguir, tomando como referencia las explotaciones más deficientes. Bajo esos postulados, los agricultores mejor preparados y con más inquietudes para adaptarse a las exigencias del mercado han encontrado en la cooperativa un freno a sus pretensiones: la cooperativa ha sido un competidor a la hora de rentabilizar su maquinaria, les ha privado del acceso a la propiedad de fincas de emigrantes, han tenido que orientar sus cultivos a los productos comercializados por las cooperativas, $y$ han debido cultivar en arrendamiento o aparcería con pocas expectativas de inversión en la explotación.

Puede parecer que en estas palabras hay cierto ensañamiento contra el cooperativismo, pero esto es ajeno a las pretensiones del análisis. El desarrollo rural es una necesidad y para que brillen sus ventajas las cooperativas han de corregir las deficiencias. 
En ese sentido hay que realzar el nuevo enfoque del cooperativismo que aportan las Sociedades Agrarias de Transformación (S.A.T.). Las SAT son empresas cooperativas que agrupan habitualmente a un pequeño número de agricultores unidos por razones de eficacia económica (el número mínimo de micmbros para construir una S.A.T. es de tres). De esa manera se viene a conjugar la individualidad con $\mathrm{cl}$ asociacionismo aprovechando lo positivo de ambos.

En la provincia de Zaragoza, la S.A.T. con mayor número de socios tiene 25 y son frecuentes las de 8-10 agricultores. En Huesca hay algunas S.A.T. cerealistas de 50 y hasta 90 socios, pero son las excepciones. Ya ha pasado la ctapa en que "estaba mal visto" no pertenecer a la cooperativa, y se viene constatando en la realidad que hay socios que abandonando o no la cooperativa, se constituyen en S.A.T. porque entienden que a su través defienden mejor sus intereses.

La entrada de España en la CEE ha propiciado que las cooperativas o S.A.T. hayan de potenciarse porque a su través se canalizan las ayudas comunitarias. Concretamente, la política de precios de la CEE se instrumenta mediante las Organizaciones de Productores Agrarios (OPA) sobre las que actúan los mecanismos comunitarios de intervención y retirada de productos. Y para erigirse una OPA es condición imprescindible el hecho cooperativo. La legislación vigente considera que tanto los productos hortofrutícolas como los cereales (trigo, cebada, avena, centeno, maiz y sorgo), el lúpulo, el algodón y el aceite de oliva son susceptibles de acogerse a los beneficios de las O.P.A., pero siempre bajo el régimen de cooperativa o S.A.T. (vid. legislación en bibliografía final).

En este marco, a las cooperativas y S.A.T. corresponde un papel primordial de cara al desarrollo agrario. Ya no se trata de cuestiones políticas que "impongan" o fomenten fórmulas asociativas; sino que la supervivencia económica de muchos agricultores actuales depende del asociacionismo. La CEE se ha provisto de una dotación legal y presupuestaria para ayudar a los agricultores, y para ello se sirve del instrumento cooperativo; lo que se requiere ahora en el campo aragonés es que las entidades asociativas depuren sus deficiencias para que esas ayudas tengan la finalidad prevista.

\section{CONCLUSIONES}

Se ha dicho al principio que el cooperativismo es un fenómeno de trascendencia social y económica, y en las líneas precedentes ha quedado de manifiesto; también se ha puesto en evidencia que tiene ventajas e inconvenientes para el desarrollo rural. El entorno económicosocial del campo aragonés es muy diferente del que dió lugar a la difusión del cooperativismo en los años cincuenta y sesenta, de mancra que actualmente la contribución del asociacionismo a la cficacia productiva del sistema agrario es fundamental. Por eso adquieren tanta importancia los inconvenientes del cooperativismo tradicional que en su mayor pare han actuado de lastre en el camino hacia la modernización del sector.

La Política Agraria de la Comunidad se apoya en el asociacionismo, de manera que no se puede prescindir de él, aunque la dirección del sector vaya hacia fórmulas de mercado cada vez. menos proteccionistas. En este contexto es imprescindible que el asociacionismo agrario responda a las necesidades reales del campo aragonés, lo que significa que hay que reforzar sus ventajas y climinar sus inconvenientes. 
No es este el marco para definir una política de cooperativas lo cual se nos antoja pretencioso y hasta frívolo. No obstante, estas reflexiones debieran servir para llamar la atención acerca de la situación de crisis del asociacionismo agrario aragonés y de la conveniencia de reorientar su estructura para hacerla más acorde con las demandas del medio económico de Aragón, entendido como una región integrada en la CEE.

\section{BIBLIOGRAFIA}

ALMARCHA, L. (1965): La cooperación como sistema económico social. Obra sindical de Cooperación. Madrid.

BLUMANN, C. (1985): Las organizaciones de productos y la política agrícola de la CEE. Rev. de Estudios Agrosociales, 133. Madrid.

CASTILlO, J.J. (1978): Proletarios muy pobres. Planteamientos básicos para el estudio de la Confederación Nacional Católico-Agraria (1917-42). Rev. Agricultura y Sociedad nº6. Madrid.

CABALlER, V. (1986): Gestión y Conlabilidad de Cooperativas Agrarias. $3^{2}$ edición. Ed. Mundi-Prensa. Madrid.

CABALLER, V. y otros (1987): Economía de la cooperativa hortofrutícola. $\mathrm{M}^{2}$ de Agricultura y Ed. Aedos en coedición. $2^{2}$ edición. Madrid.

CANALEJO, P. (1982): El nuevo estatuto reglamentario de las S.A.T. la reforma de la legalidad cooperativa. Ag. Sociedad. $\mathrm{n}^{\circ}$ 23. Madrid.

CERDA, B. (1959): El régimen cooperativo. Ed. Bosch. Tomo I. Doctrina e Historia de la cooperación. Barcelona.

ESCRIBANO, C. (1985): Todo sobre la cooperativa. Col. Legal de Vechi. Barcelona.

GONZALEZ, V. (1968): Desarrollo de la comercialización. Documentos de Educación Cooperativa, $\mathrm{n}^{2} 5$. Zaragoza.

RUBIO, J.L. (1986): El cooperativismo agrario aragonés. Institución Femando el Católico. Zaragoza.

VALDES, F. (1975): Las cooperativas de producción. Ed. Montecorvo. Madrid.

VARIOS (1972): Análisis Económico y Sociologico del Cooperativismo agrario. CECA. Madrid.

\section{LEGISLACION ACTUAL}

- Ley 3/1987, de 2 de abril, General de Cooperativas.

- R.D. 1776/1981, de 3 de agosto, por el que se aprueba el Estatuto que regula las Sociedades Agrarias de Transformación.

- Ley 29/1972, de 22 de junio, de Agrupaciones de Productores Agrarios.

- R.D. 1706/1984, de 30 de agosto, sobre determinación de mínimos exigibles a los productores hortofrutícolas para acogerse a la ley de A.P.A.

- R.D. 1101/1986, de 6 de junio, por el que se regula la constitución de O.P.A. de frutas y hortalizas.

- R.D. 23 de octubre de 1985, $\mathrm{n}^{2}$ 2155/85. CEREALES. Agrupaciones de Productos agrarios.

- R.D. 459/1986, de 21 de febrero. Agrupaciones de Lúpulo y sus Uniones.

- R.D. 1706/1986, de 2 de mayo, por el que se regula la constilución de A.P.A. de Algodón y sus Uniones.

- R.D. 2796/1986, de 19 de diciembre, por cl que se regula el reconocimiento de O.P.A. de Aceite de oliva y sus Uniones. 